\title{
Subjetividades do trabalho de enfermeiros no processo de doação de órgãos: sociopoética como método
}

\author{
Subjectivities of nurses 'work in the organ donation process: sociopoetic as a method \\ Subjetividades del trabajo del enfermero en el proceso de donación de órganos: la sociopoética \\ como método
}

\section{Resumo}

O objetivo deste artigo foi desvelar as subjetividades do trabalho de enfermeiros no processo de doação de órgãos com a utilização da sociopoética como método. Pesquisa qualitativa, desenvolvida com 8 enfermeiros, atuantes em município do extremo sul do estado da Bahia, Brasil. A produção de dados considerou o grupo-pesquisador como dispositivo e o estímulo dos sentidos, para expressão das subjetividades. As atividades desenvolvidas na dinâmica do grupo-pesquisador foram gravadas e os áudios transcritos, textualizados e categorizados, segundo análise de conteúdo de Bardin. $\mathrm{O}$ estudo cumpriu as exigências éticas da pesquisa com seres humanos. Os resultados estão apresentados em quadro, a partir dos seguintes temas transversais das subjetividades expressas pelo estímulo do sentido: imprevisibilidade do cotidiano, importância do trabalho em equipe, humanização e acolhimento e esperança como elemento motivador para o trabalho. A discussão expressou que o uso da sociopoética como método possibilitou desvelar a dimensão imaginativa dos profissionais de enfermagem sobre suas atividades, analisando diversos aspectos, como o desvelar das subjetividades do trabalho de enfermeiros no processo de doação de órgãos, nos depoimentos de enfermeiros e das dimensões presentes no processo de trabalho de doação de órgão e tecidos no âmbito hospitalar, dentre outros aspectos dos conteúdos emergentes do Grupo Pesquisador. Assim, percebeu-se a imprevisibilidade do cotidiano, a importância do trabalho em equipe, a humanização e acolhimento e a esperança, como elementos motivadores para o trabalho e fatores que influenciam na doação e no transplante de órgãos.

Palavras-chave: Enfermagem; Doação de órgãos e tecidos; Transplantes.

\begin{abstract}
The objective of this article was to reveal the subjectivities of nurses' work in the process of organ donation with the use of sociopoetics as a method. Qualitative research, developed with 8 nurses, working in a municipality in the extreme south of the state of Bahia, Brazil. The production of data considered the researcher group as a device and the stimulus of the senses, for the expression of subjectivities. The activities developed in the dynamics of the researcher group were recorded and the audios were transcribed, textualized and categorized, according to Bardin's content analysis. The study fulfilled the ethical requirements of research with human beings. The results are presented in a table, based on the following transversal themes of the subjectivities expressed by the stimulus of meaning:
\end{abstract}


unpredictability of everyday life, importance of teamwork, humanization and welcoming and hope as a motivating element for work. The discussion expressed that the use of sociopoetics as a method made it possible to unveil the imaginative dimension of nursing professionals about their activities, analyzing several aspects, such as unveiling the subjectivities of nurses' work in the organ donation process, in the statements of nurses and the dimensions present in the work process of organ and tissue donation in the hospital environment, among other aspects of the emerging content of the Research Group. Thus, it was perceived the unpredictability of daily life, the importance of teamwork, humanization and welcoming and hope, as motivating elements for work and factors that influence organ donation and transplantation.

Keywords: Nursing; Tissue and organ procurement; Transplantes.

\section{Resumen}

El objetivo de este artículo fue dar a conocer las subjetividades del trabajo de las enfermeras en el proceso de donación de órganos con el uso de la sociopoética como método. Investigación cualitativa, desarrollada con 8 enfermeras, trabajando en un municipio del extremo sur del estado de Bahía, Brasil. La producción de datos consideró al grupo de investigadores como un dispositivo y el estímulo de los sentidos, para la expresión de subjetividades. Se grabaron las actividades desarrolladas en la dinámica del grupo de investigadores y se transcribieron, textualizaron y categorizaron los audios, según el análisis de contenido de Bardin. El estudio cumplió con los requisitos éticos de la investigación con seres humanos. Los resultados se presentan en una tabla, a partir de los siguientes temas transversales de las subjetividades expresadas por el estímulo de sentido: imprevisibilidad de la vida cotidiana, importancia del trabajo en equipo, humanización y acogida y esperanza como elemento motivador del trabajo. La discusión expresó que el uso de la sociopoética como método permitió desvelar la dimensión imaginativa de los profesionales de enfermería sobre sus actividades, analizando varios aspectos, como desvelar las subjetividades del trabajo de las enfermeras en el proceso de donación de órganos, en las declaraciones de enfermeras. y las dimensiones presentes en el proceso de trabajo de la donación de órganos y tejidos en el ámbito hospitalario, entre otros aspectos del contenido emergente del Grupo de Investigación. Así, se percibió la imprevisibilidad de la vida cotidiana, la importancia del trabajo en equipo, la humanización y la acogida y la esperanza, como elementos motivadores del trabajo y factores que influyen en la donación y el trasplante de órganos.

Palabras clave: Enfermería; Adquisición de órganos y tejidos; Trasplantes.

\section{Introdução}

No intuito de tratar ou minimizar o sofrimento causado por enfermidades de elevado grau de complexidade, o transplante de órgãos pode ser considerado como alternativa necessária, onde os profissionais enfermeiros ocupam papel de grande relevância nesse cenário (Knihs, Magalhães, Santos, Wolter \& Paim, 2019).

Para que esse procedimento obtenha êxito, é necessário que aconteça a doação para o transplante dos órgãos que, de modo geral, se dá por meio de um processo que envolve diversas etapas. É importante ressaltar que a divisão didática das etapas não significa que a realização de algumas delas se dê em separado, podendo ocorrer sobreposição de alguns pontos, por exemplo: a partir da identificação do potencial doador, deve-se realizar a notificação para a Central de Notificação, Captação e Distribuição de Órgãos (CNCDO), e enquanto essa ação é executada, o potencial doador já deve estar submetido à manutenção térmica e volêmica, de modo que se tente manter mais ajustada o possível a estabilidade hemodinâmica e as funções cardiorrespiratórias. Assim, enquanto essa manutenção é feita, o Protocolo para avaliação da Morte Encefálica (ME) também deve estar em andamento. Em continuidade, ao passo da constatação da ME, prosseguem-se a entrevista familiar ao transplante (Silva, Tavares, Fonseca, Marcondes, de Souza, \& de Souza, 2015).

A entrega pessoal ou comprometimento dos profissionais de saúde, em especial, dos enfermeiros no processo de doação ao transplante também pode ser considerada como fator determinante para o sucesso desse procedimento, uma vez que comprometer-se com o trabalho pode significar exigência de si com um máximo nível de produtividade e rendimento. Com isso, esses profissionais se veem na necessidade de se empenharem ao máximo nas vivências do cotidiano profissional (Silva, Tavares Fonseca, Oliveira, Sodré \& de Souza, 2018).

Dessa forma, a maneira como o indivíduo percebe e se relaciona com o mundo representa a manifestação de sua subjetividade, a qual é produzida entre uma multiplicidade de instâncias individuais, coletivas e institucionais (Tavares, 2015). Exemplo disso são os comportamentos e percepções relacionados à prática profissional que podem demonstrar manifestações 
importantes da subjetividade dos profissionais enfermeiros que atuam no processo de doação ao transplante de órgãos e tecidos, já que as características de suas atividades cotidianas têm relação com a produção de subjetividade desse profissional (Fonseca, Tavares, Silva, Paiva, \& de Oliveira Augusto, 2016).

Com o intuito de valorizar a subjetividade de enfermeiros que atuam no processo de doação ao transplante de órgãos e tecidos foi utilizada a sociopoética na ativação de processos de criação deste estudo. A sociopoética pode ser considerada uma abordagem do conhecimento do ser humano e da sociedade, que transforma poeticamente a realidade em estudo para melhor conhecer, a partir de cinco princípios básicos (Tavares, 2016):

- Grupo-Pesquisador (GP) como dispositivo: não se trata apenas de uma técnica de pesquisa, mas um quadro onde diversas técnicas podem ser desenvolvidas, onde o pesquisador usa um "tema orientador" como ponto de partida para chegar àquilo que ele quer. Nesse sentido, "cada participante da pesquisa está ativo em todas as suas etapas, dentre elas, produção de dados, leituras analíticas e transversais desses dados, e socialização, e pode interferir no devir da pesquisa".

- Importância do sentido espiritual e humano, das formas e dos conteúdos no processo de construção de saberes: atentar para a dimensão espiritual, humana e política do cuidar em Enfermagem, a fim de implementar cuidados e desenvolver projetos de ensino e de investigação de qualidade, visando à satisfação do cliente e do profissional.

- Importância do corpo como fonte de conhecimento: existe a possibilidade de se perceber o corpo como desencadeador de potências criadoras, por meio de oficinas, com uso de técnicas artísticas.

- Papel da criatividade de tipo artística no aprender, no conhecer e no pesquisar: "ao privilegiarem formas artísticas de produção de dados, os sociopoetas colocam em jogo capacidades criadoras que mobilizam o corpo inteiro e revelam fontes não conscientes de conhecimento - fontes que muitos (...) ignoravam possuir antes do decorrer da pesquisa" (Gauthier, 2012, pág.74). Com isso, o desenvolvimento de ações que interfiram na criatividade das pessoas, independentemente do ambiente em que possam estar inseridos.

Portanto, o objetivo do presente artigo foi desvelar as subjetividades do trabalho de enfermeiros no processo de doação de órgãos com a utilização da sociopoética como método.

\section{Metodologia}

Trata-se de uma pesquisa exploratória de campo, de abordagem qualitativa e fundamentada na sociopoética (Tavares, 2016). Para a produção de dados, adotou-se o grupo-pesquisador como dispositivo para os participantes arquitetarem conhecimentos de maneira coletiva, conferindo-lhes poder para certificação de competências do grupo.

Participaram do estudo oito enfermeiras e enfermeiros que atuavam no processo de doação e transplante de órgãos de um município do extremo sul do estado da Bahia, Brasil.

Inicialmente, se definiu como participantes do estudo os profissionais da equipe multiprofissional, envolvidos no processo doação/transplante. Foram distribuídos quatorze convites entre os sujeitos elegíveis, entretanto, compareceram à entrevista em grupo pesquisador oito profissionais de Enfermagem, que atenderam ao seguinte critério de inclusão: trabalhar há mais de seis meses no processo de doação/transplantes, na área de abrangência de uma Organização de Procura de Órgãos (OPO) no Extremo Sul da Bahia, Brasil. Foram excluídos da pesquisa profissionais que não consentiram com sua participação, mesmo que convidados e esclarecidos sobre os procedimentos do estudo.

Os dados utilizados nesta pesquisa foram colhidos e a pesquisa foi finalizada no primeiro semestre do ano de 2016. Para esta produção, conforme propõe a sociopoética (Tavares, 2016), foi constituído o Grupo Pesquisador (GP) com os enfermeiros $\mathrm{O}$ encontro foi realizado, numa sala de aula cedida por uma instituição de ensino superior privado do município estudado, e teve duração de três horas e meia.

A produção de dados realizada junto ao grupo pesquisador deu-se por meio da utilização de técnicas criativas 
(Ribeiro, 2020) com recurso de desenho, que permitiu ao grupo expressar suas emoções mais intrínsecas acerca das questões que nortearam os diálogos que surgiram das próprias falas dos participantes, na busca pelo esclarecimento de questões do cotidiano de trabalho dos participantes.

O encontro do GP correu da seguinte maneira:

- Dinâmica inicial de relaxamento com o grupo;

- Confecção de mandala dos sentidos, com a eleição pelo Grupo-Pesquisador do seguinte Tema Gerador: O processo de doação de órgãos e transplantes no hospital. Seguindo a descrição das etapas da dinâmica com a ordem, de acordo os órgãos de sentido: Tato, Visão, Paladar, Audição;

- Finalização com breve momento de análise e coffe breack.

Segue a descrição das etapas da dinâmica segundo os órgãos dos sentidos:

- O facilitador entregou uma folha de papel com o desenho de uma mandala onde havia divisões e explicou todos os passos da dinâmica, informando que iria trabalhar com os órgãos dos sentidos, apresentando os materiais expressivos ao grupo. Informou ainda que cada profissional deveria identificar-se com um nome figurado que representaria cada sujeito o material produzido deveria ser confeccionado respondendo ao tema gerador previamente negociado: o processo de doação de órgãos e transplantes no hospital.

O trabalho grupal foi gravado com a autorização do grupo pesquisador e os áudios foram transcritos, textualizados e categorizados, segundo análise de conteúdo de Bardin (Bardin, 1994).

Após a textualização e categorização das falas dos enfermeiros participantes, com o intuito de organizar a disposição dos depoimentos, foi confeccionado um quadro que retrata a síntese de categorização dos conteúdos emergentes das falas dos participantes na dinâmica mandala dos sentidos, onde foi feito um resumo dos relatos dos participantes, sendo dispostos conforme o sentido a que foi atribuída, destacando-se o tema transversal da subjetividade expressa pelo estímulo do sentido.

O estudo foi aprovado por um Comitê de Ética em Pesquisa com seres humanos, sob o protocolo de n. ${ }^{\circ} 996.669$, CAAE n. ${ }^{\circ} 33743514.7 .0000 .5243$, tendo os participantes assinado o Termo de Consentimento Livre e Esclarecido (TCLE), respeitando-se, desta forma, os princípios éticos que cabem às pesquisas com seres humanos, como disposto na Resolução n. ${ }^{\circ}$ 466/2012 do CNS - Conselho Nacional de Saúde (Brasil, 2012).

\section{Resultados}

Foram desveladas as subjetividades do trabalho de enfermeiros no processo de doação de órgãos no âmbito hospitalar com a utilização da sociopoética como método. Para facilitar o entendimento dos depoimentos dos enfermeiros, optou-se por explorar essas subjetividades, conforme a produção de dados em cada sentido.

Com o intuito de organizar a disposição das falas dos participantes do segundo momento, o Quadro 1 retrata a síntese de categorização das falas dos participantes na dinâmica mandala dos sentidos, onde foi feito um resumo, realizando a síntese de cada fala dos participantes. Com isso, foram dispostos os depoimentos de cada participante conforme o sentido a que foi atribuída, destacando-se o tema transversal da subjetividade expressa pelo estímulo do sentido: 
Quadro 1: Síntese de categorização das falas dos participantes na dinâmica dos sentidos.

\begin{tabular}{|c|c|c|c|c|c|c|}
\hline \multicolumn{2}{|r|}{ Caracterização } & \multicolumn{5}{|c|}{ Categoria } \\
\hline \multirow[t]{2}{*}{$\mathrm{N}^{\circ}$} & \multirow[t]{2}{*}{ Sujeito } & \multicolumn{4}{|c|}{ Sentido Temático } & \multirow[t]{2}{*}{ Sentido Simbólico } \\
\hline & & Tato & Visão & Paladar & Audição & \\
\hline 1 & Doe-se & $\begin{array}{l}\text { A apresentação do } \\
\text { profissional a } \\
\text { família deve se } \\
\text { dar de forma } \\
\text { propícia, pois é } \\
\text { um momento } \\
\text { doloroso, e muitos } \\
\text { não possuem } \\
\text { conhecimento } \\
\text { relacionado à } \\
\text { doação de órgãos. }\end{array}$ & $\begin{array}{l}\text { É necessária a } \\
\text { ampliação da visão } \\
\text { da sociedade diante } \\
\text { do que realmente é } \\
\text { a doação de órgãos, } \\
\text { mesmo que tal ação } \\
\text { demore em surtir o } \\
\text { efeito esperado. }\end{array}$ & $\begin{array}{l}\text { A abordagem feita } \\
\text { ao familiar que se } \\
\text { dá no início do } \\
\text { processo de } \\
\text { doação é } \\
\text { importante, já que } \\
\text { o acolhimento no } \\
\text { primeiro contato } \\
\text { se torna } \\
\text { primordial para o } \\
\text { sucesso da } \\
\text { proposta da } \\
\text { equipe. }\end{array}$ & & $\begin{array}{l}\text { Tato: primeiro } \\
\text { contato. Visão: } \\
\text { Processo de } \\
\text { crescimento. } \\
\text { Paladar: } \\
\text { Sorriso }\end{array}$ \\
\hline 2 & Assis-tência & $\begin{array}{l}\text { Processo de } \\
\text { doação de órgãos, } \\
\text { especialmente } \\
\text { quando se trata de } \\
\text { crianças, possui } \\
\text { grandes desafios a } \\
\text { serem vencidos, } \\
\text { promovendo, não } \\
\text { só à família, mas } \\
\text { também à equipe, } \\
\text { maior comoção no } \\
\text { desenvolvimento } \\
\text { das ações } \\
\text { necessárias. }\end{array}$ & & $\begin{array}{l}\text { É necessária uma } \\
\text { atuação eficaz da } \\
\text { equipe diante da } \\
\text { família para o } \\
\text { esclarecimento da } \\
\text { importância da } \\
\text { doação dos órgãos }\end{array}$ & $\begin{array}{l}\text { Todo o esforço } \\
\text { promove } \\
\text { benefícios para } \\
\text { a equipe e para } \\
\text { os familiares } \\
\text { que podem ser } \\
\text { observados na } \\
\text { qualidade de } \\
\text { vida do paciente } \\
\text { transplantado. }\end{array}$ & $\begin{array}{l}\text { Tato:Criança difícil } \\
\text { e complicado de } \\
\text { trabalhar. } \\
\text { Paladar: Ação. } \\
\text { Audição: Vida. }\end{array}$ \\
\hline 3 & Humani-zação & $\begin{array}{l}\text { O trabalho deve } \\
\text { ser realizado em } \\
\text { união para que o } \\
\text { objetivo proposto } \\
\text { seja alcançado }\end{array}$ & $\begin{array}{l}\text { Fazer uso em todo o } \\
\text { processo da doação } \\
\text { e captação de } \\
\text { órgãos das políticas } \\
\text { de humanização. }\end{array}$ & $\begin{array}{l}\text { A postura } \\
\text { profissional pode } \\
\text { fazer toda a } \\
\text { diferença no } \\
\text { processo de } \\
\text { captação dos } \\
\text { órgãos (“ética"). }\end{array}$ & $\begin{array}{l}\text { Trabalhar de } \\
\text { forma digna em } \\
\text { prol de outras } \\
\text { vidas, } \\
\text { valorizando } \\
\text { cada pessoa } \\
\text { desde a } \\
\text { concepção até a } \\
\text { morte. }\end{array}$ & $\begin{array}{l}\text { Tato: } \\
\text { Parceria.Visão: } \\
\text { Acolher e } \\
\text { transformação. } \\
\text { Paladar: Sensibili- } \\
\text { dade. Audição: } \\
\text { valoriza-ção, } \\
\text { esperança. }\end{array}$ \\
\hline 4 & $\begin{array}{l}2^{\mathrm{a}}(?) \text { Esperan- } \\
\text { ça }\end{array}$ & $\begin{array}{l}\text { Cada protocolo } \\
\text { aberto tem } \\
\text { finalidade, mas } \\
\text { traz uma } \\
\text { consternação nos } \\
\text { profissionais } \\
\text { devido aos } \\
\text { desafios } \\
\text { encontrados no } \\
\text { decorrer do } \\
\text { processo. }\end{array}$ & $\begin{array}{l}\text { Mesmo sendo } \\
\text { árduo, o processo de } \\
\text { captação de órgão } \\
\text { promove sempre um } \\
\text { gozo ao fim da } \\
\text { doação. }\end{array}$ & $\begin{array}{l}\text { Diante de toda a } \\
\text { problemática } \\
\text { gerada no } \\
\text { cotidiano dos } \\
\text { profissionais que } \\
\text { atuam na doação } \\
\text { de órgão, há } \\
\text { contentamento no } \\
\text { fim do processo. }\end{array}$ & $\begin{array}{l}\text { O processo de } \\
\text { doação concede } \\
\text { ao receptor uma } \\
\text { nova } \\
\text { oportunidade de } \\
\text { viver. }\end{array}$ & $\begin{array}{l}\text { Tato: Desconhe- } \\
\text { cimento. Visão: } \\
\text { Beleza. Paladar: } \\
\text { Dificulda-des e } \\
\text { sucesso. Audição: } \\
\text { Nascimen-to. }\end{array}$ \\
\hline 5 & $\begin{array}{l}\text { Trabalho e } \\
\text { Dedicação }\end{array}$ & $\begin{array}{l}\text { É necessária a } \\
\text { aplicação da } \\
\text { educação } \\
\text { continuada para a } \\
\text { construção e } \\
\text { adequação do } \\
\text { conhecimento da } \\
\text { equipe que } \\
\text { trabalha com } \\
\text { doação de órgãos. }\end{array}$ & $\begin{array}{l}\text { Para se atingir } \\
\text { metas é preciso uma } \\
\text { união de todos os } \\
\text { integrantes da } \\
\text { equipe em prol da } \\
\text { consolidação do } \\
\text { processo de } \\
\text { captação de órgãos. }\end{array}$ & $\begin{array}{l}\text { O processo de } \\
\text { aprendizado deve } \\
\text { ser constante, } \\
\text { buscando sempre } \\
\text { o aperfeiçoamento } \\
\text { principalmente na } \\
\text { abordagem } \\
\text { familiar. }\end{array}$ & $\begin{array}{l}\text { Motivação para } \\
\text { trabalhar na } \\
\text { doação de } \\
\text { órgãos reside na } \\
\text { sensação de } \\
\text { realizar } \\
\text { atividade de } \\
\text { grande } \\
\text { relevância. }\end{array}$ & $\begin{array}{l}\text { Tato: Ampliar a } \\
\text { visão, trabalho em } \\
\text { equipe. Visão: } \\
\text { Constru-ção. } \\
\text { Paladar: Educação } \\
\text { continuada. } \\
\text { Audição: Emoção }\end{array}$ \\
\hline
\end{tabular}




\begin{tabular}{|c|c|c|c|c|c|c|}
\hline 6 & Vida & & $\begin{array}{l}\text { O processo de } \\
\text { doação de órgãos ao } \\
\text { transplante pode ser } \\
\text { considerado como } \\
\text { uma ajuda mútua, } \\
\text { trazendo satisfação } \\
\text { tanto à equipe } \\
\text { quanto às famílias. }\end{array}$ & $\begin{array}{l}\text { Mesmo diante de } \\
\text { tantas } \\
\text { adversidades no } \\
\text { desempenhar das } \\
\text { atividades para a } \\
\text { captação dos } \\
\text { órgãos, há } \\
\text { satisfação quanto } \\
\text { ao transplante } \\
\text { realizado. }\end{array}$ & $\begin{array}{l}\text { A doação de } \\
\text { órgãos traz } \\
\text { como retorno e } \\
\text { possibilidade } \\
\text { vida com maior } \\
\text { qualidade. }\end{array}$ & $\begin{array}{l}\text { Visão: Globaliza- } \\
\text { ção } \\
\text { Paladar: Alegria e } \\
\text { esperança. } \\
\text { Audição: } \\
\text { Esperança. }\end{array}$ \\
\hline 7 & $3^{a}$ Esperança & $\begin{array}{l}\text { A necessidade de } \\
\text { atuar, levando a } \\
\text { sociedade ao } \\
\text { entendimento } \\
\text { acerca da } \\
\text { relevância de ser } \\
\text { doador e a } \\
\text { respeito dos } \\
\text { benefícios que a } \\
\text { doação trás para a } \\
\text { população. }\end{array}$ & & $\begin{array}{l}\text { Todo o processo } \\
\text { traz certa aflição } \\
\text { diante dos } \\
\text { conflitos em torno } \\
\text { do familiar do } \\
\text { doador e do } \\
\text { receptor. }\end{array}$ & $\begin{array}{l}\text { O } \\
\text { comprometimen } \\
\text { to e empenho da } \\
\text { equipe e de cada } \\
\text { um } \\
\text { individualmente } \\
\text { facilita o } \\
\text { processo do } \\
\text { trabalho. }\end{array}$ & $\begin{array}{l}\text { Tato: Angústia. } \\
\text { Paladar: Vida e } \\
\text { angústia. } \\
\text { Audição: Ajudar, } \\
\text { Disposi-ção, } \\
\text { tranquili-dade e } \\
\text { satisfação. }\end{array}$ \\
\hline 8 & $1^{\mathrm{a}}$ Esperança & $\begin{array}{l}\text { O processo de } \\
\text { doação apresenta } \\
\text { certa } \\
\text { imprevisibilidade } \\
\text { no que tange a } \\
\text { ocorrência de } \\
\text { situações } \\
\text { inesperadas que } \\
\text { podem atrapalhar } \\
\text { a captação de } \\
\text { órgãos. }\end{array}$ & $\begin{array}{l}\text { As dificuldades } \\
\text { encontradas nos } \\
\text { fechamentos de } \\
\text { protocolos são } \\
\text { muitas, tornando } \\
\text { incerta a captação } \\
\text { dos órgãos. }\end{array}$ & $\begin{array}{l}\text { O processo de } \\
\text { doação e captação } \\
\text { de órgãos ao } \\
\text { transplante possui } \\
\text { dois extremos: a } \\
\text { dor da família em } \\
\text { luto, e o júbilo da } \\
\text { família do } \\
\text { receptor. }\end{array}$ & $\begin{array}{l}\text { Um grande } \\
\text { obstáculo é } \\
\text { levar os } \\
\text { familiares dos } \\
\text { doadores a } \\
\text { entender o } \\
\text { protocolo de } \\
\text { morte } \\
\text { encefálica. }\end{array}$ & $\begin{array}{l}\text { Tato: Desconhe- } \\
\text { cimento. } \\
\text { Visão:Persseveranç } \\
\text { a } \\
\text { Paladar: Tristeza e } \\
\text { alegria. } \\
\text { Audição: Desafio. }\end{array}$ \\
\hline & $\begin{array}{l}\text { Tema trans- } \\
\text { versal da } \\
\text { subjeti-vidade } \\
\text { expres-sa pelo } \\
\text { estímu-lo do } \\
\text { sentido }\end{array}$ & $\begin{array}{l}\text { Imprevisibili-dade } \\
\text { do cotidiano }\end{array}$ & $\begin{array}{l}\text { Importância do } \\
\text { trabalho em equipe }\end{array}$ & $\begin{array}{l}\text { Humanização e } \\
\text { acolhimento }\end{array}$ & $\begin{array}{l}\text { Esperança como } \\
\text { elemento } \\
\text { motivador para } \\
\text { o trabalho }\end{array}$ & \\
\hline
\end{tabular}

Fonte: Autores.

Na síntese das falas dos enfermeiros podem ser identificados inúmeros depoimentos que traduzem aspectos subjetivos do cotidiano de cada participante conforme o sentido a que foi atribuída, destacando-se o tema transversal da subjetividade expressa pelo estímulo dos sentidos.

\section{Discussão}

A partir da leitura da síntese dos depoimentos descritos na tabela contida nos resultados do estudo vinculado a este artigo, foi possível desvelar subjetividades do trabalho de enfermeiros no processo de doação de órgãos no âmbito hospitalar, com a utilização da sociopoética como método.

O grupo foi formado a partir de um convite para a discussão de um determinado tema gerador, que tanto pode ser oferecido pelo pesquisador-oficial, como por meio de uma demanda do próprio grupo, ou ainda a partir de uma negociação entre os interesses de ambos. Uma vez formado o grupo, o pesquisador-oficial elabora as oficinas nas quais será trabalhado o tema escolhido, participando da produção como mais um olhar (embora sem perder de vista a relação de poder que envolve a sua participação). 
O GP foi parte ativa de todo o processo, participando da produção de dados, além da análise e da socialização dos mesmos (Fonseca, 2017). A importância das culturas dominadas e de resistência levam em conta valores, visões próprias, crenças, interações com variadas culturas e experiências pessoais de crescimento de todos os integrantes do grupo. Esta orientação, diretamente, aponta para outras maneiras de interpretar o mundo (Gauthier, 2012, pág.74).

Desse modo, podem ser encontrados na síntese das falas dos enfermeiros, relatos que demonstram aspectos subjetivos do cotidiano de cada participante, conforme o sentido a que foram atribuídos.

Com o estímulo ao sentido do tato, foi possível verificar por meio da fala do grupo que, o processo de doação de órgãos no hospital possui inúmeras adversidades. Dentre elas, ressalta-se a imprevisibilidade, que pode ser considerada como mais transversal e subjetiva apontada por um dos participantes da oficina, podendo ser um fator limitante do êxito na doação e no transplante de órgãos.

A hipótese de não se conseguir prever ou antecipar de forma lógica o que poderá ocorrer, como parte do processo de trabalho tende a oportunizar alguns tipos de tensões que são realmente uma característica de serviços de saúde relacionados ao processo de doação ao transplante de órgãos (Knihs, Magalhães, Santos, Wolter \& Paim, 2019),

O processo de transplantes no hospital possui características peculiares com elevado grau de complexidade. Portanto, exige grande desenvoltura por parte daqueles que executam atividades relacionadas a esse processo.

Ainda como característica do trabalho dos enfermeiros no processo de doação de órgãos no hospital, ao estimular o sentido da visão, outro tema que surgiu de caráter subjetivo diz respeito à importância do trabalho em equipe, apontada por um dos participantes da oficina.

Dado o grau de complexidade que o tema envolve, a equipe multiprofissional deve ser capaz de suprir as necessidades de cuidado do potencial doador e da família, dispondo de conhecimentos atualizados, trabalhando em conjunto com os demais setores do hospital para realizar atuação rápida, segura e eficaz (Soares, Brito, Magedanz, França, Araújo \& Galato, 2020). Isso poderá promover otimização do processo de doação de órgãos e transplantes nos hospitais, dando a condição de que outros pacientes também possam se beneficiar das doações (Tavares, 2014).

No intuito de ajudar a salvar vidas, são projetadas ações de profissionais de saúde atuantes em doação e transplantes de órgãos e tecidos nos hospitais onde a obtenção e viabilização de órgãos para os receptores motivam e dão significado ao trabalho (Chaparro, 2017).

O pessoal de saúde que atua na doação de órgãos ao transplante deve realizar suas tarefas cotidianas de maneira alinhada, não somente com os parâmetros preestabelecidos pelos órgãos de saúde, mas suas atitudes devem ser pautadas também na forma como o processo de trabalho passou a ser construído nas equipes.

Quando o sentido do paladar foi estimulado, possibilitou-se entender na fala do grupo, como temática mais transversal e subjetiva apontada por um dos participantes da oficina, a necessidade da humanização e acolhimento no processo de doação e transplantes no hospital.

Para os profissionais da doação e do transplante, em especial, os enfermeiros, humanizar significa oferecer ajuda aos familiares do doador falecido, para que possam mobilizar mecanismos de enfrentamento, diante de situações complexas como a da situação de morte encefálica, permitindo falar com tais familiares de forma adequada (Silva, 2020). A empatia foi um dos recursos mais usados, para compreensão da situação, sentimentos, comportamentos e sofrimentos (Lara, León-Correa \& Navarrete-Campos, 2018). Com isso, os familiares tendem a estabelecer laços de confiança com os profissionais enfermeiros que estão prestando assistência, sendo esse, um exemplo de fator que pode desencadear a doação de órgãos e tecidos.

Para conseguir prestar assistência de qualidade aos familiares e pacientes, os profissionais de saúde inseridos nas diferentes etapas do processo de transplante e doação, e direcionados às necessidades específicas dos sujeitos, buscam desenvolver acolhimento e a humanização do cuidado. Por meio de relações dialógicas que proporcionam desenvolvimento a 
cada pessoa, são respeitados, dentre outros aspectos, a individualidade, as crenças, a linguagem e as características pessoais (Silva, Tavares, Fonseca, Marcondes, de Souza, \& de Souza, 2015).

A necessidade de humanizar atendimento e cuidado está vinculada aos diferentes modos de fazer, adequados às necessidades dos usuários. É fundamental, prestar atendimento com responsabilidade e resolutividade, não banalizando o sofrimento, nem tratando com superficialidade as demandas do usuário (Chaparro, 2017).

Nos serviços de saúde, é notória a necessidade de acolher bem os usuários (Tavares, 2019). No que diz respeito à doação e aos transplantes de órgãos, isso se multiplica, pois as famílias que podem estar passando por momento muito difícil de suas vidas precisam ainda mais desse acolhimento e de cuidado humanizado.

Quando foi estimulada a audição, a característica que pode ser considerada como mais transversal e subjetiva e que foi apontada por um dos participantes da oficina se trata da esperança, elemento motivador para o trabalho.

Para compreender a importância da esperança, ressalta-se que no processo de doação ao transplante de órgãos, os familiares têm que trabalhar dois momentos quando se trata da morte encefálica, sendo inicialmente a aceitação da realidade da perda, seguida da aflição (Yang \& Wu, 2018). Verifica-se, então, a necessidade de apoio emocional para auxiliá-los a encontrarem forças para vivenciar essas emoções, num momento da vida em que a maior parte dos indivíduos encontra-se fortemente fragilizado (Tavares, 2021). A autorização da doação conforta e ajuda a dar sentido à morte do familiar, por outro lado, não poder conhecer os receptores é uma grande frustração para a família, a qual convive com essa expectativa (Barros, Silva, Guedes \& Pessoa, 2017).

Então, o surgimento e a elucidação de elementos motivadores, como a esperança, no processo de doação de órgãos no hospital, devem permear o processo de trabalho dos profissionais que atuam nesse campo. Contudo, existe sempre aflição nos profissionais e familiares, causadas pela angústia que emerge do processo, e que também pode ser superada pelo contentamento que vem ao se dar conta de que ouve êxito na doação.

Ao desenvolver atividades utilizando elementos da sociopoética, como método de produção de dados, ressalta-se a importância da "ação dialógica", teorizada, que caracteriza uma ação cultural norteada pelos quatro princípios, a saber: a) colaboração: os sujeitos se encontram para a transformação do mundo em colaboração; o importante é que os saberes das pessoas são colocados em diálogo, possibilitando que cada uma aprenda com a outra, sem nenhuma hierarquia; b) união para a libertação: esse princípio prediz a unificação com o Eu; a desmistificação da realidade; a não divisão entre conhecimento, afeto e agir; a solidariedade de classe; e a descoberta de si como sujeito singular; c) organização: refere-se a organizar com coerência, ousadia, radicalização, valentia de amar, crença, clareza das condições, adesão ao grupo por simpatia; e d) síntese cultural: prediz a dialética permanência-mudança, Investigação temática, Problematização, Teoria da ação educativa (Tavares, 2016).

\section{Considerações Finais}

Por meio da pesquisa expressa neste artigo, foi possível chegar à compreensão de uma série de fatores que influenciam o trabalho dos profissionais que atuam no processo de doação ao transplante de órgãos e tecidos.

Foi possível conseguir alcançar a meta estabelecida no objeto geral deste artigo, que foi desvelar as subjetividades do trabalho de enfermeiros no processo de doação de órgãos, com a utilização da sociopoética como método. Esse objetivo foi alcançado através dos depoimentos de enfermeiros e das dimensões presentes no processo de trabalho de doação de órgão e tecidos no âmbito hospitalar, dentre outros aspectos dos conteúdos emergentes do Grupo Pesquisador. Também foram identificados os seguintes temas transversais da subjetividade expressos pelo estímulo do sentido: Imprevisibilidade do cotidiano, Importância do trabalho em equipe, Humanização e acolhimento e Esperança como elemento motivador para o trabalho. 
Percebeu-se, com isso, que a imprevisibilidade pode ser um fator limitante do êxito na doação e no transplante de órgãos. No momento em que estiverem atuando no processo de doação de órgãos no hospital, os profissionais de saúde precisam atentar para a forma como é realizado o contato com os familiares de potenciais doadores, para demonstrar segurança e estabelecer laços de confiança mútua, alicerçada pela humildade e valorização do outro.

Nisto, mesmo com todas as dificuldades cotidianas, os profissionais e familiares mantém acesa a esperança na resolução final das situações. Essa esperança é citada no transcorrer da oficina como motivadora para a continuação de tarefas e superação de barreiras e dificuldades. Para isso, devem ocorrer: oportunidade de aplicar novos conhecimentos, aprender a trabalhar em equipe, enriquecimento da aprendizagem por meio de mobilização de recursos internos, e entendimento da necessidade da diversificação da atuação nos cenários onde são desenvolvidas as práticas laborais.

O uso da Sociopoética como método possibilitou desvelar a dimensão imaginativa dos profissionais que atuam no processo de doação ao transplante no âmbito hospitalar sobre o seu processo de trabalho, entendendo diversos aspectos.

Apontam-se como limitações do estudo: dificuldades no processo de produção de dados da pesquisa relacionadas à falta de apoio da gestão do município e ao atraso de duas horas na chegada dos participantes no local previamente definido para o encontro; a lacuna de um diálogo multidisciplinar, uma vez que dos 14 convidados das diversas categorias profissionais que atuavam no processo de doação ao transplante no cenário em questão, apenas 08 enfermeiros participaram.

Finalmente, valoriza-se aqui a participação do profissional enfermeiro, uma vez que o estudo poderá ter aplicabilidade no enfrentamento de vivências cotidianas daqueles que atuam no processo de doação ao transplante de órgãos e tecidos.

\section{Referências}

Bardin, L. (1994). Análise de conteúdo. São Paulo: Edições 70.

Barros, L. B. F., Silva, L. D. F. D., Guedes, M. V. C., \& Pessoa, V. L. M. D. P. (2017). Cuidado clínico de enfermagem fundamentado em Parse: contribuição no processo de transcendência de transplantados cardíacos. Revista Gaúcha de Enfermagem, 38.

Brasil. (2012). Resolução CNS nº466, de 12 de dezembro de 2012. https://bvsms.saude.gov.br/bvs/saudelegis/cns/2013/res0466_12_12_2012.html.

Chaparro, G. R. (2017). La presunción de la donación de órganos en Colombia: reflexiones para el debate. Revista Latinoamericana de Bioética, 17(2), 92106.

Fonseca, P. I. M. N., Silveira, P. G., Tavares, C. M. M., \& Carvalho, J. C. (2017). A Plasticidade Criativa Possibilitada Pela Sociopoética: A Perspectiva Da Criação De Relaxamentos. Revista Portuguesa De Enfermagem De Saúde Mental, V. Especial, 99-106.

Fonseca, P. I. M. N., de Melo Tavares, C. M., Silva, T. N., Paiva, L. M. D. P. M., \& de Oliveira Augusto, V. (2016). Family interview for organ donation: necessary knowledge according to coordinators in organ transplants. Revista de Pesquisa: Cuidado é fundamental online, 8(1), 3979-3990.

Fonseca, P. I. M. N., Balistieri, A. S., \& de Melo Tavares, C. M. (2016). Produção de subjetividade dos sujeitos envolvidos na entrevista para doação de órgãos: olhar da enfermagem. Revista Cubana de Enfermería, 32(2).

Gauthier, J. (2012). O oco do vento: metodologia da pesquisa sociopoética e estudos transculturais. Curitiba: CRV.

Knihs, N. D. S., Magalhães, A. L. P., Santos, J., Wolter, I. D. S., \& Paim, S. M. S. (2019). Doação de órgão e tecidos: utilização de ferramenta de qualidade para a otimização do processo. Escola Anna Nery, 23.

Lara, L., León-Correa, F. J., \& Navarrete-Campos, J. P. (2018). Análisis de actitudes hacia las donaciones de órganos en población chilena. Persona y Bioética, 22(1), 121-133.

Ribeiro, I. M. O. C., Tavares, C., \& Carvalho, J. C. (2020). Terapias complementares nas emoções: uma perspectiva sociopoética. Revista ROL de Enfermería, 43(1), 204-211.

Silva, T. N., Tavares, C. M. M., da Fonseca, P. I. M. N., Marcondes, F. L., de Souza, R. C., \& de Souza, L. M. (2015). The performance of health professionals in the process of organ donation: integrative review. Revista Enfermagem Atual [Internet], 74(12).

Silva, T. N., Tavares, C. M. M., Fonseca, P. I. M. N., Oliveira, J. F., Sodré, A. C. B. M., \& de Souza R. C. (2018). Trabalho do enfermeiro em doação/transplante de órgãos: nuances de um compromisso com a vida. Saúde Coletiva, 44(8).

Silva, L. B., Tavares, C., \& Tavares, M. M. (2020). Proceso de enseñanza-aprendizaje en salud en el escenario de las tecnologías digitales de información y comunicación. Research, Society And Development, 9, p. 234-244.

Soares, L. S. D. S., Brito, E. S. D., Magedanz, L., França, F. A., Araújo, W. N. D., \& Galato, D. (2020). Transplantes de órgãos sólidos no Brasil: estudo descritivo sobre desigualdades na distribuição e acesso no território brasileiro, 2001-2017. Epidemiologia e Serviços de Saúde, 29 , e2018512. 
Research, Society and Development, v. 10, n. 12, e163101219850, 2021

(CC BY 4.0) | ISSN 2525-3409 | DOI: http://dx.doi.org/10.33448/rsd-v10i12.19850

Tavares, C. M. M. (2016). Como desenvolver experimentações estéticas para produção de dados na pesquisa sociopoética e abordagens afins? Revista PróUniversus, 7(3).

Tavares, C. M. D. M., Pastor, A. D. A., Paiva, L. M. D., \& Lima, T. O. (2021). Innovations in the teaching-learning process of psychiatric nursing and mental health. Revista Brasileira de Enfermagem, 74.

Tavares, C. M., \& Mesquita, L. M. (2019). Sistematização da assistência de enfermagem e clínica ampliada: desafios para o ensino de saúde mental. Enfermagem em foco, 10(7).

Tavares, C. M. D. M., Muniz, M. P., \& Silva, T. (2015). Prioridades de investigação em saúde mental e a transformação do modelo assistencial. Revista Portuguesa de Enfermagem de Saúde Mental, (SPE2), 107-112.

Tavares, C. M., Medeiros, C. \& Gama, L. (2014). Práticas inovadoras de ensino-aprendizagem no curso de graduação em enfermagem da Universidade Federal Fluminense. Espaço para a Saúde (Online), 15, 591-598.

Yang, T., \& Wu, Y. (2018). Ethical disputes over living organ transplant and the applicable solutions to these disputes in China. Acta bioethica, 24(2), 219225. 